\title{
Animalidad y bestialidad: la expresión del instinto en la poesía de Juan Gelman
}

\author{
Amandine GUILLARD \\ Universidad Nacional de Córdoba-CONICET \\ amandine.guillard@hotmail.fr \\ $\&$
}

\section{Resumen}

Este artículo propone abordar los conceptos de animalidad y bestialidad en la poesía de Juan Gelman. A pesar de ser poco estudiados, son omnipresentes en su poesía y reflejan algunas de las inquietudes del poeta: la dictadura, el exilio, la ausencia, la muerte, el amor, la poesía. Será interesante ver por qué Gelman recurre a estos dos conceptos para expresar preocupaciones fundamentales y sentimientos contradictorios: desde la bestialidad de los verdugos hasta el dolor animal de la madre, pasando por las múltiples sensaciones del poeta exiliado de su tierra natal y padre -como él mismo lo expresa- huérfano de su hijo.

Palabras claves: Animalidad, Bestialidad, Poesía, Juan Gelman, Dictadura argentina, Exilio.

\begin{abstract}
This article deals with the concepts of animality and bestiality in Juan Gelman's poetry. Although rarely studied, they are nonetheless part and parcel of his poetry, as they express some of the poet's preoccupations: dictatorship, exile, absence, death, love. It will be interesting to see why Gelman uses these two aspects to reflect basic preoccupations and contradictory feelings: from the executioners's bestiality to the mothers's utmost pain, not to mention the numerous feelings of the
\end{abstract}


poet himself, exiled from his native country and an orphan to his son, as he calls himself.

Key words: Animality, Bestiality, Poetry, Juan Gelman, Argentinian dictatorship, Exile

\section{Introducción}

En el año 2011, el poeta argentino Juan Gelman vino a recitar sus poemas en la Universidad Nacional de Córdoba, acompañado por el músico Rodolfo Mederos. En esa ocasión, tuvimos la oportunidad de intercambiar unas pocas e informales palabras con él, en particular, aprovechamos la ocasión para hacerle la pregunta siguiente: "ipor qué hay tantos animales en su poesía?". Su respuesta, clara e inesperada fue: "para hacerme compañía". En su momento, después de haber dedicado un año a estudiar la función simbológica de los animales en su poesía, nos quedamos boquiabierta ${ }^{1}$. Pero luego, esta respuesta simple y sincera no solamente nos confirmó la precisa función poética de cada una de las especies sino que visibilizó también la importancia y la necesidad, para el poeta y para el hombre, de llenar ausencias, curar dolores y poner palabras sobre vivencias difíciles de racionalizar.

Este trabajo no pretende analizar la función simbólica de las más de cien especies animales observadas en distintos poemarios compuestos entre 1971 y $2000^{2}$; sería demasiado ambicioso. Sin embargo, sí nos parece adecuado interesarnos por dos términos genéricos particularmente recurrentes: "animal" y

1 Escribimos una tesis de maestría, todavía inédita, titulada la función simbólica de los animales en la poesía de Juan Gelman. Universidad de Poitiers, Francia, 2009.

2 La junta luz (1982, París), de palabra (1971-1987, París, Roma, Calella de la Costa, Madrid, Ginebra, Zúrich), Valer la pena (1996-2000, Méjico). 
"bestia". Al igual que cada una de las especies animales que pueblan la poesía de Gelman, ambos términos tienen funciones determinadas y nos proponemos exponerlas aquí, y poner particular énfasis en analizar la manera cómo esas dos figuras participan de la expresión de sensaciones inefables, ligadas a su situación de exiliado, de padre de desaparecido y de ferviente oponente a la última dictadura argentina (1976-1983) .

\section{El animal o el instinto puro}

En la poesía de Juan Gelman, el sustantivo "animal" está generalmente relacionado con la idea de instinto que, a su vez, tiene varios significados y referentes. Ante todo, conviene precisar que, a diferencia del término "bestia", "animal" puede aparecer en contextos muy positivos, para transmitir un profundo bienestar, por ejemplo: "Así verá la raíz incompleta de la belleza, su felicidad animal, [...]" (Gelman, 2001, p.75); pero, muchas veces, es una figura negativa:

$[\ldots]$

le dan 220 voltios a la boca que anunciaba el reino de la

Revolución/

picana en la cabeza que soñaba acostada en las almohaditas

de la Revolución/

220 voltios en los labios de las vaginas/despedazando sus

cielos/

ya no van a salir hijos por ahí/ni liras/ni baguales/

va a salir puro odio por ahí/no vuelo/no hermanitos/

están torturando el jugo de las vaginas de mi país/

el jugo de mi país parece un animal/ [...] (“la mesa”, Gelman, 2002, p.349)

Aquí, el animal nos evoca varias cosas a la vez. En primer lugar, puede remitir a la destrucción - propiamente dicha- del órgano femenino durante una sesión de tortura. No hay que olvidar que la última dictadura argentina alcanzó niveles inimaginables en términos de crueldad ${ }^{4}$. Si bien la violación

3 Recordemos que gran parte de los poemas del corpus han sido compuestos durante el exilio del poeta en Europa, provocado por la persecución política de la cual fue víctima durante la última dictadura argentina (1976-1983). Si él pudo sobrevivir, no fue el caso de muchos de sus compañeros de militancia (Rodolfo Walsh, Haroldo Conti, Paco Urondo, etc.), ni tampoco de su hijo Marcelo Ariel Gelman que fue secuestrado junto con su mujer encinta.

4 Es importante aclarar aquí que la última dictadura instauró un régimen de terror sin precedente en Argentina, provocando la desaparición de más de 30.000 personas y el encarcelamiento 
mencionada en este poema fue un tormento que sufrieron ambos géneros, cabe decir que existió un ensañamiento particular para con el cuerpo de las mujeres, considerado un "receptáculo" del odio militar ${ }^{5}$. Al representar a las víctimas por la zona corporal torturada, se pone énfasis en el dolor y en las secuelas irreversibles ocasionadas; la figura del animal aquí sugiere pues que el órgano femenino perdió sus características humanas - "ya no van a salir hijos por ahî" - y, en ese sentido, se volvió casi "irreconocible" por parte de mentes y ojos humanos, debido a la reiteración de las torturas.

Asimismo, recordemos que, a partir del año 1976, se instauró una nueva instancia en los tormentos, al ser infligidos a personas "desaparecidas". En efecto, en los centros clandestinos de detención (CCD) - fuera del marco judicial legal-, todo era posible, y fue lo que incrementó la crueldad en las sevicias que no tenían ni límite de duración ni límite de brutalidad. Estas aclaraciones ayudan a entender la comparación gelmaniana del "jugo de las vaginas [que] parece un animal". Al ser vejada, la mujer perdió la seguridad y la "impenetrabilidad" de sus fronteras corporales y se vio reducida a sufrir la invasión y el dolor que la impregnaron totalmente. A su vez, la sinécdoque "vaginas" - que designa anónimamente a las mujeres violadas - transmite una sensación de multitud en la medida en que no se distingue cuál mujer ha sido vejada y cuál no, precisamente porque la violación se perpetró de manera sistemática en los CCD, como tortura y arma de guerra:

La violencia sexual contra las mujeres en los centros clandestinos de detención lleva implícito un mensaje no dirigido únicamente hacia ellas. La violación y el abuso en sus diferentes formas son actos terroristas cometidos desde el aparato estatal con el objeto de sembrar miedo indiscriminadamente.

No se trata sólo del mensaje brutal que las castiga por haberse salido de los moldes que la sociedad patriarcal les adjudica: hijas, esposas, madres y amantes. El terrorismo sexual es un arma de guerra con varias funciones. (Lewin y Wornat, 2014, p.187)

por razones políticas de 12.000 más. Con la colaboración de todas las instituciones, se puso en aplicación el método represivo del secuestro-tortura-asesinato llevado a cabo en aproximativamente 600 centros clandestinos de detención. Estas tres palabras son los términos reales que corresponden a los eufemismos utilizados por los militares, heredados de la Guerra de Argelia: detención, interrogatorio y desaparición. Respecto a esta cuestión, es muy interesante consultar el libro de Robin, Marie-Monique, (2004). Les escadrons de la mort, l'école française. París: La Découverte.

5 Por más informaciones, invito el lector a consultar el artículo de Amandine Guillard, Poétique du corps enfermé. Répression et résistance des prisonnières politiques argentines (1976-1983) Amerika [En línea] (ISSN: 2107-0806), № 11, 2014, puesto en línea el 25 de diciembre de 2014, Laboratoire Interdisciplinaire de Recherche sur les Amériques, Rennes. [http://amerika.revues.org/5514]. 
En ese sentido, la sinécdoque "vaginas" parece, por un lado, representar a todas las mujeres argentinas; y, por otro lado, denunciar que la violación a gran escala no solamente lastimó a las víctimas directas sino que hirió y traumatizó al cuerpo social en su conjunto.

En segundo lugar, es muy probable que la figura del animal remita al estado de desprotección en el cual se encontraron las mujeres secuestradas durante la dictadura. En una situación límite como lo fue la tortura, el instinto de supervivencia puede haber sustituido las convicciones ideológicas que tenían las personas antes del secuestro. Este aspecto remite al hecho de que la magnitud de la represión - adentro y afuera de los CCD - desembocó en que muchos militantes llegaran a los campos de concentración, según los términos de Pilar Calveiro (2006), "derrotados":

Los militantes caían agotados. El manejo de concepciones políticas dogmáticas como la infalibilidad de la victoria, que se deshacían al primer contacto con la realidad del "chupadero" [CCD]; la sensación de acorralamiento creciente vivida durante largos meses de pérdida de los amigos, de los amigos, de los compañeros, de las propias viviendas, de todos los puntos de referencia [...] eran sólo algunas de las razones por las que el militante caía derrotado de antemano." (pp.20-21)

Expuesto a una situación traumática, el ser humano tiende a convertirse en instinto puro y pierde, de alguna manera, su capacidad de reflexión: el cuerpo y la cesación del dolor físico se transforman pues en prioridad absoluta. Por esta razón, la animalidad evocada por Gelman encarna tanto la desprotección y la destrucción buscadas por el aparato represivo, lo que remite al testimonio de un sobreviviente del CCD La Perla (provincia de Córdoba):

Uno es puro, cuando llega a esos lugares llega con sus ideales. La tortura en el fondo no es para matar, es para destruir al hombre, porque él sirve para traer a otro hombre. [...] Todos los compañeros que pasaron por ese lugar quisieron morirse, pero eran dioses, y no te dejaban. (Anónimo, en H.I.J.O.S, 2008, p.15)

Desde una perspectiva literaria, es interesante observar que el término "animal" suele aparecer en el marco de una comparación clara o implícita. Pero el poeta no solamente lo vincula con la tortura, como en el ejemplo anterior, sino también con la justicia o, mejor dicho, con la falta de justicia:

[...]/tristeza que

subís de paco/de los compañeros/de los

sueños que derrotaron esta vez/justicia 
como animal de fuego donde ardés

dolor/ [...] (Gelman, 2002, p.174)

En este poema, "Alguna vez", aparece una contradicción: existe la justicia pero no actúa. Si no, ¿cómo explicar la imagen del dolor en llamas? Este dolor vivo y ardiente se debe seguramente a que, en el momento de escribir estos versos, además de no haber transcurrido mucho tiempo desde la desaparición de su hijo Marcelo, de su nuera embarazada y de una gran cantidad de compañeros - Paco Urondo entre otros, mencionado aquí-, reina la impunidad en Argentina ${ }^{6}$. La imagen de la "justicia como animal de fuego" evoca pues una suerte de infierno donde los compañeros desaparecidos no encontrarán paz hasta que se condene a los genocidas. A falta de encontrar y recuperar a los cuerpos de los desaparecidos, el poema sugiere que, al menos, los culpables no queden impunes. En caso contrario, los compañeros -Urondo y demás- serán doblemente mutilados: por una parte, por ser "desaparecidos" o, según Antonia García (2000), "muertos sin sepultura" (pp.88)7 ; y, por otra parte, por no ser considerados víctimas "dignas" de ser protegidas y defendidas por la justicia.

Después de la tortura y la falta de justicia, el poeta acude a la figura del animal para expresar sentimientos resultantes de la situación de exilio en la cual se encuentra:

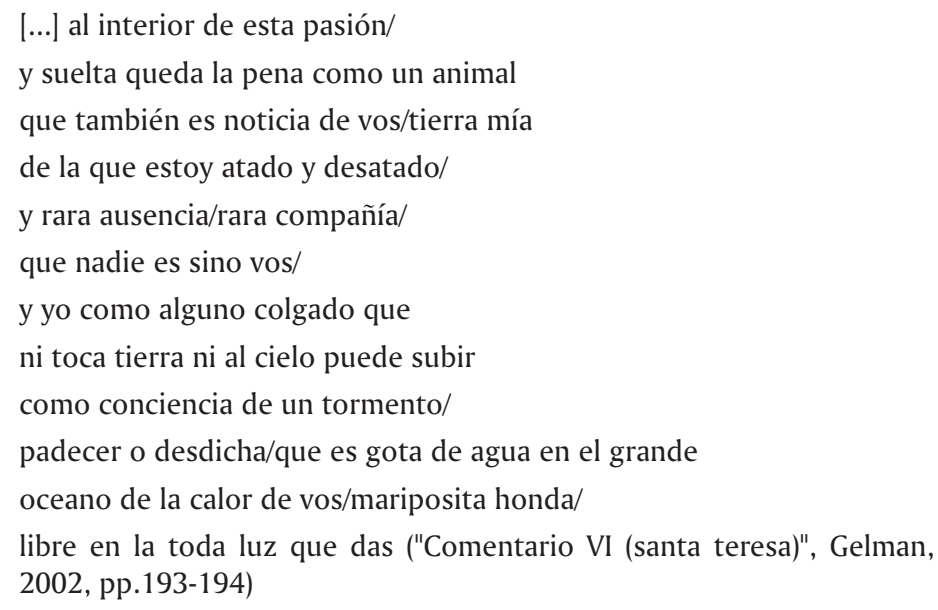

6 Recordemos que este poema forma parte de Si dulcemente, poemario compuesto y publicado en 1980 , en plena dictadura.

7 Antonia García se basa en el texto de Sófocles, Antígona, para demostrar los efectos sociales de la desaparición forzada: disuasión, obediencia, muerte biológica y política. García, Antonia, (2000), "Por un análisis político de la desaparición forzada". En: Richard, Nelly (ed.), Políticas y estéticas de la memoria, Santiago: Cuarto Propio, pp. 87-92. 
En este poema, el poeta desarraigado, "desterrado", parece estar expuesto a la más total desprotección, incapaz de controlar y domar una pena "sin riendas". En consecuencia, la "pena como un animal" es el sentimiento imposible de racionalizar, propio del exiliado que se encuentra - repentinamente y en contra de su voluntad - apartado del grupo social que lo identificaba como argentino y como parte integrante de una sociedad determinada; se ubica pues al margen de lo que Alfred Schütz (2003), filósofo austriaco, nombra "el hogar":

Para cada copartícipe, la vida del Otro pasa a ser, de tal modo, una parte de su propia autobiografía, un elemento de su historia personal. Lo que es, lo que llegó a ser y lo que será son codeterminados por su participación en las múltiples relaciones primarias actuales o potenciales vigentes en el grupo del hogar. (p.112)

Desde esta perspectiva y considerando válida la afirmación de Octavio Paz (1997) según la cual sólo existimos a través de la otredad - "la otredad es nosotros mismos. [...] sin otredad no hay unidad." (p.276)-, podemos suponer que el exiliado pierde su capacidad de "ejercer" el lazo social que establecía su pertenencia a una cultura, a un idioma, a una historia. Queda asentado, sin embargo, que la conexión entre el exiliado y su tierra natal no estuvieron "anulados", al contrario, ya que todavía - y quizás más que nunca - está "atado y desatado" de su tierra de la cual tanto siente la "rara ausencia" como la "rara compañía". Más aun, son esos sentimientos los que le hacen recordar a su tierra y permiten no olvidar, como dirá en otro poema, "las razones del exilio" (2002, p.314). Visceral y "animal", la pena exiliar lo conduce a producir la poesía que leemos aquí, impregnada de referencias al desamparo y a la vulnerabilidad propios del que está lejos del regazo maternal. El desterrado, sin referencias, ya sean espacio-temporales, culturales o sociales, se encuentra confrontado consigo mismo, lo que se manifiesta en Gelman por el resurgimiento de su ser profundo, despojado, animal:

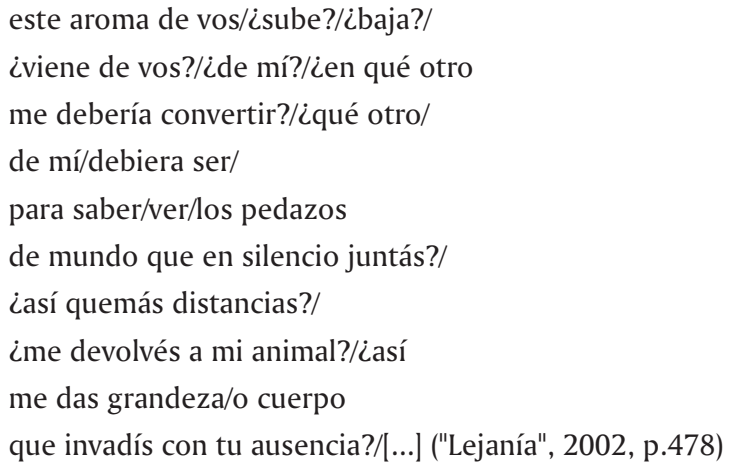


El poeta ofrece aquí la imagen de un ser herido, frágil, permeable a todos los dolores. La reiteración de las preguntas pone de relieve la situación de soledad en la cual se encuentra, asaltado por dudas imposibles de resolver. Invadido por la "presencia ausente de lo amado" (Gelman, 2008, p.2), decide llenar el insoportable silencio de palabras e interrogaciones dirigidas a su tierra natal personificada y dotada del poder de responderle. Cual mujer inalcanzable y profundamente deseada, Argentina se convierte en fuente de dolor y deseo a la vez ${ }^{8}$.

En importante señalar que la figura del animal no solamente surge en situaciones vinculadas con el exilio sino que también se manifiesta cuando el poeta se refiere a las pérdidas y ausencias en general, en particular, la de su hijo:

¿cómo será la suerte de que vuelvas?/

¿la veré acaso?/¿vendrás con tu muda

sazón?/¿tu pulso abierto?/tan mayor

el sentimiento dentro de la cuerpo?/

¿como dolor agudo?/Zausente de

su bien?/¿su pena?/¿su señora de ella?/

¿extraña soledad porque criatura

de ningún modo le hace compañía?/

¿abrasarás con sed/con responsables?/

¿siempre muriendo?/¿los idiomas otros

hablarás?/¿cantarás?/¿dónde tu cáliz

no apartarás para que todos hombren?/

¿adjuntaditos por tu consolar?/

¿como animales apretados?/ [...] ("XI", Gelman, 2002, p.140)

Este poema forma parte de Carta abierta, poemario compuesto entre París y Roma en 1980 y dedicado a su hijo desaparecido: Marcelo Ariel. Gelman concluye con una nota explicativa donde cuenta del secuestro de su hijo y nuera, y aclara que "hasta que no vea sus cadáveres o a sus asesinos, nunca los dar[á] por muertos" (2002, p.155). Esta frase tiene eco en los lemas de las "Madres de Plaza de Mayo" que reclamaban por la "aparición con vida" de sus hijos en los años $80^{9}$. Gelman recuperó el cuerpo de su hijo asesinado recién en el año

8 Nos extendimos sobre esta cuestión en otro trabajo: Guillard, Amandine, (2014). "L’ambiguiité de la figure féminine dans Interrupciones 2 de Juan Gelman", en Rita [en línea] (ISSN: 2102-6424), $\mathrm{N}^{\circ} 7$, París: IHEAL, Institut des Hautes Études de l’Amérique Latine. [http://www.revue-rita.com/ regards7/-ambiguite-de-la-figure-feminine-dans-interrupciones-2-de-juan-gelman.html].

9 Este aspecto lo desarrolla Ana Longoni (2007) en su libro Traiciones donde explica que la "inaudibilidad" del discurso de los sobrevivientes lleva a los familiares de desaparecidos, en los años 80, a negarse "a reconocer (al menos públicamente) que la inmensa mayoría de 
1989; desde ahí, hay varios elementos de este poema que podemos comprender mejor. Más precisamente, la reiteración de las preguntas y, por ende, la sensación de desorientación y de ansiedad que transmite. Las interrogaciones incesantes pueden remitir a la total incertidumbre en la cual se encontraban todos los padres de desaparecidos, desesperados por enterarse de la suerte de sus hijos.

Asimismo, el cambio voluntario de género - "la cuerpo"-; los errores de ortografía y neologismos - "abrasarás", "hombren"- participan de la creación de una atmósfera confusa donde el lector también se plantea las razones de esas "desobediencias" linguiísticas. Si bien, por un lado, son características de la poesía conversacional ${ }^{10}$; por otro lado, crean un efecto poético cierto que transcribe el estado anímico del poeta. La asociación del artículo femenino "la" con el sustantivo masculino "cuerpo" sugiere que el poeta sospecha de la posible deformación o destrucción del cuerpo de su hijo. Sin saber con exactitud que la desaparición significaba la muerte, esta errata voluntaria demuestra que el poeta dudaba en encontrar a su hijo no solamente con vida, sino también y sobre todo íntegro. Anhelando cumplir con su rol natural de padre, la figura del animal lo ayuda pues en verbalizar su primera y primitiva necesidad: proteger a su hijo ("¿adjuntaditos por tu consolar?/¿cómo animales apretados?/").

Como lo habremos observado, la figura del animal puede tener muchos significados y aparecer en contextos inesperados, supliendo, a veces, la figura humana, como en "Otras partes":

$$
\begin{aligned}
& \text { ¿oíste/corazón?/nos vamos } \\
& \text { con la derrota a otra parte/ } \\
& \text { con este animal a otra parte/ } \\
& \text { los muertos a otra parte/ }
\end{aligned}
$$

los desaparecidos fue sistemáticamente asesinada" a pesar de la gran cantidad de relatos testimoniales. (p.24)

10 Recordemos que la poesía de Juan Gelman se inscribe en un contexto histórico-social de violencia que atravesaba no solamente Argentina sino América Latina en su conjunto. Determinó pues, en gran parte, la emergencia de movimientos literarios de rupturas o "transgresión" representativos de lo que Roberto Fernández Retamar denominó el "cansancio de las formas", y que dará lugar a la "poesía conversacional" o "coloquial" más anclada en la realidad política y cuyas principales características son la representación del habla diario, el uso del voseo, del lenguaje coloquial apartado de los esquemas canónicos (errores de ortografía, barras oblicuas, uso de puntación inapropiada, abreviaciones, etc.). En Fernández Retamar, Roberto. En: Bay Alemany, Carmen. "Para una revisión de la poesía conversacional". En Bay Alemany, Carmen. Residencia en la poesía: poetas latinoamericanos del siglo XX. Cuadernos de América sin nombre $\mathrm{N}^{\circ} 13$. Alicante: Universidad de Alicante, 2006, p. 162. 
Amandine Guillard

que no hagan ruido/callados como están/ni

se oiga el silencio de sus huesos/

sus huesos son animalitos de ojos azules/

se sientan mansos a la mesa/[...] (2002, p.351)

En este poema, se puede notar que Gelman recurre a una variante del término genérico "animal": "animalito". Mientras "animal", en la primera estrofa, puede ser sinónimo de "derrota" o "carga", parecer que "animalito" tiene otro significado, más cercano a la idea de protección. En efecto, si se considera que la sinécdoque "sus huesos" designa a los muertos-desaparecidos, se puede deducir que los "animalitos" son, a su vez, los compañeros desaparecidos. Pero ¿cuál sería la razón y la función poética de la animalización de los huesos? Recordemos que este poema forma parte del poemario Hacia el sur, compuesto entre 1981 y 1982, durante el periodo dictatorial pero también en un momento en que ya iban saliendo a la luz algunos testimonios y documentos sobre los horrores cometidos ${ }^{11}$. En consecuencia, el poeta tenía cada día más conocimiento de lo que podía haber pasado en Argentina. Por esta razón, se puede considerar que los "huesitos" son la representación la más "plausible" del estado físico de las personas desaparecidas en el momento de la escritura del poema. Vencido ante la fuerte probabilidad de no encontrar al cuerpo de sus amigos y familiares, el poeta consigue mantenerlos en vida en su poesía mediante figuras regenerativas. Desde esta perspectiva, la animalización confiere a los difuntos un cuerpo nuevo, alejado de la envoltura humana destruida y torturada, y dotado del poder de guiarse en la noche dictatorial gracias a sus ojos azules ${ }^{12}$.

En otras oportunidades, la figura animal interviene para expresar, además del dolor del poeta, el dolor de las Madres de Plaza de Mayo. El animal ya no es el cuerpo protector del desaparecido sino la encarnación del dolor materno, como lo ilustra La junta luz (1980):

11 Por ejemplo, fue en 1981 que la Comisión Argentina de Derechos Humanos publicó un libro de poemas compuestos en las cárceles dictatoriales: CADHU, Desde la cárcel, presos políticos argentinos. México: Asociación de Escritores de México. Por otro lado, se empieza a dar a conocer una serie de testimonios clave, desde el exilio, de sobrevivientes que estuvieron secuestrados mucho tiempo en CCD y pudieron aportar muchas informaciones. Un ejemplo emblemático es el de Carlos Raimundo Moore, quien recorrió distintos CCD entre 1974 y 1980 y brindó testimonio en 1980 ante el Alto Comisionado de las Naciones Unidas para los Refugiados. En Robles, Miguel, (2010). Córdoba: Ediciones del pasaje, pp.264-265.

12 En efecto, encontramos una extraña correlación entre el hecho de que los ojos de los "animalitos" sean "azules" y la teoría de Plinio el Viejo (1772) según la cual los ojos cuyo color se acercara más al "verde mar" verían mejor en la oscuridad. (p.357) Histoire naturelle, tomo 4, libro XI, París: Desaint. 


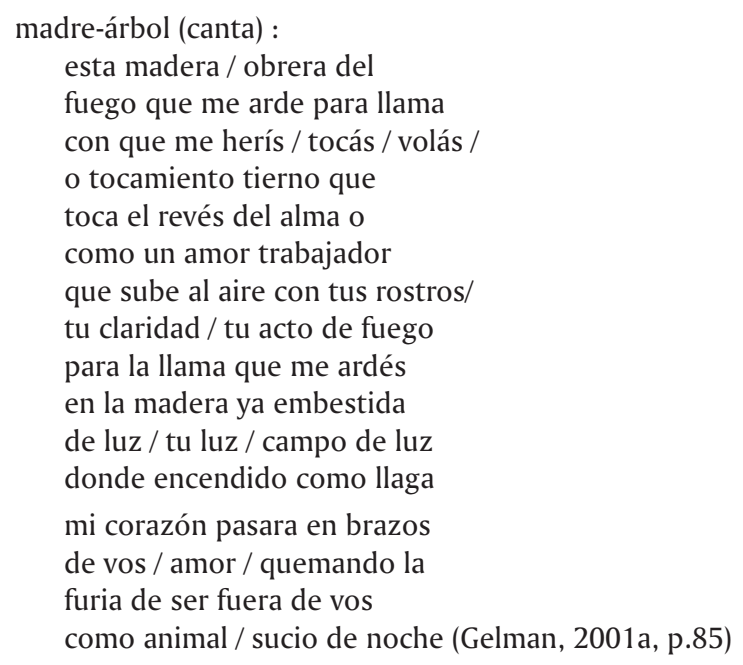

La figura animal aparece aquí en un contexto donde la pasión domina la razón ${ }^{13}$. La furia de la madre separada de su hijo se manifiesta a través de un discurso catártico donde el instinto materno se asemeja al instinto animal, guiado por la supervivencia. De hecho, no es anodina la transformación de la madre en "madre-árbol", vulnerable a todas las intemperies (fuego, viento, lluvia), por un lado; pero, por otro lado, profundamente enraizada en la tierra. La metamorfosis de la madre en árbol permite realizar una conexión y una comunicación inaudita entre el cielo y la tierra, como si la madre-árbol fuera capaz de buscar y encontrar a su hijo en cualquier parte del cosmos. Símbolo también de la columna vertebral, las madres-árboles aparecen aquí como los pilares de una sociedad que requiere de esta fuerza vital para que se haga memoria y justicia. Pero, pese a ser capaces de remover cielo y tierra, las madres no pueden ni eludir ni ignorar el dolor inconmensurable que se manifiesta a través de una figura animal enigmática y oscura. El animal "sucio de noche" aparece pues en un contexto fuera de control. Si las madres de desaparecidos tienen la fuerza, la racionalidad y la entereza para buscar y reclamar por sus hijos, también existe la otra faceta menos visible: la de la desesperación y la espera cotidiana, la angustia y los dolores físicos por no saber nada de sus hijos, así como el sentimiento de impotencia frente a la maquinaria represiva, etc. Las Madres no son solamente las de los pañuelos en las plazas, solidarias entre ellas y acompañadas por una parte de la población. En efecto, al margen de esta imagen pública, existe otra: privada, determinada por lo intolerable de

13 Recordemos que La junta luz es una obra mezcla de poesía y teatro que pone en escena una madre de Plaza de Mayo que reclama por su hijo. 
la sobrevivencia diaria, esa "furia de ser fuera de[l hijo]", la de enfrentarse con la realidad y la desaparición cada mañana, la de constatar que la habitación del hijo sigue vacía pero intacta, cual santuario donde se intente conservar los olores y las marcas del ser querido.

A causa de la desaparición de su hijo, la animalidad de la madre -latenteresurge para dominar el cuerpo y la razón. Sin embargo, es este dolor insoportable e imposible de calmar el que impulsó, al mismo tiempo, la búsqueda incasable del hijo: "como animal sediento que/busca las aguas/tierra mía/te busco/o alma de volar/para rodearte como vuelo [...]" (Gelman, 2001a, p.91). El estado de total acecho en el cual se encuentra la madre es el disparador principal de la praxis, de la verbalización del dolor y de la elaboración de un discurso opositor al emitido por el poder autoritario. De hecho, es a partir del despertar de este sentimiento visceral que se creó la Asociación de Madres de Plaza de Mayo, el 30 de abril de 1977, en plena dictadura y vigente hasta hoy ${ }^{14}$.

\section{La bestia o la pérdida de humanidad}

La "visceralidad" del dolor y de los sentimientos resultantes de una situación límite no solamente está expresada mediante la figura del animal sino también de la bestia y, en ciertos casos, pueden llegar a cumplir funciones similares. Si ya observamos y analizamos el hecho de que el animal puede tener connotaciones tanto positivas como negativas, no es el caso de la bestia que casi siempre se ve asociada con un elemento negativo. Por ejemplo, del mismo modo que el término "animal", "bestia" puede estar estrechamente ligado al dolor ardiente provocado por la ausencia:

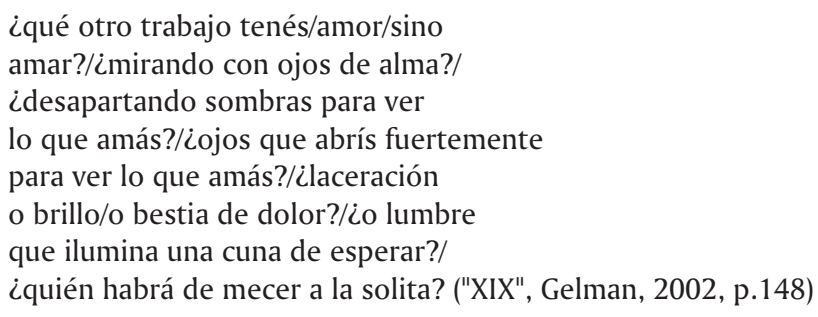

14 Su valentía y audacia ante los verdugos tendrán como consecuencia el secuestro y el asesinato de tres fundadoras de la asociación: Esther Ballestrino, María Ponce, Azucena Villaflor. Sus cuerpos serán identificados en 2005 y probarán la existencia de los "vuelos de la muerte"». En CELS, (2005), "Los crímenes del terrorismo de Estado: la fuerza de la verdad, el tiempo de la justicia", en Informe 2005, Programa Memoria y Lucha contra la Impunidad del Terrorismo de Estado, dirigido por Carolina Varsky, Valeria Barbuto, Florencia Plazas. Recuperado el 23 de abril de 2008 de: http://www.cels.org.ar/common/documentos/Informe2005_capitulo1_memoria.pdf. 
En este extracto de "XIX", queda en evidencia que la "bestia de dolor" tiene alguna correlación con el dolor de las madres por estar "fuera" del hijo. Si Gelman hizo un gran espacio en su poseía a la "furia" de las madres, no niega y no calla su propio dolor de padre. Si no supiéramos que este poema está dedicado a su hijo, al igual que todo el poemario Carta abierta, algunos elementos nos dejan vislumbrar la pena del poeta-padre, en particular, la triste presencia de la "cuna de esperar". La figura de la "bestia" es entonces otra forma de describir lo insoportable de un dolor imposible tanto de aliviar cuanto de nombrar. En efecto, se advierte que la experimentación de la muerte ajena ocasionó una dificultad, para el poeta, de poner palabras en sentimientos hasta ahora desconocidos. Ello nos remite pues a la reflexión de Cristina Piña (1993) quien recuerda que, de manera general, los escritores que sufrieron una situación límite se encontraron ante la dificultad de expresarla a partir de esquemas tradicionales ya existentes:

\begin{abstract}
Los hechos resultaban tan terribles que no alcanzaban para comprenderlos o representarlos los sistemas éticos y estéticos tradicionales, por lo cual, quienes quisieron articularlos literariamente se vieron en la necesidad de recurrir a estrategias de descentramiento apoyadas en la alusión, el eufemismo, la alegoría, el desplazamiento, la representación paródica; la metaforización en general. (p.125)
\end{abstract}

Si las palabras "animal" y "bestia" sirven ambas para describir y traducir poéticamente sensaciones resultantes del exilio es que, de alguna forma, el poeta quiere manifestar la "expulsión" física y linguiística experimentada a partir del desarraigo y del periodo dictatorial. Desde ahí, se puede suponer que quizás acuda a las figuras del animal y de la bestia porque, precisamente, remiten a sensaciones, experiencias y conceptos que exceden la razón humana, como él mismo lo expresó:

El ser humano creó las lenguas y hace cosas que ellas no pueden nombrar. El ser humano está dentro y fuera de la lengua. La poesía, lengua calcinada, tuvo que padecer en nuestro Sur discursos mortíferos, tuvo que atravesarlos y no salió indemne, pero sí más rica. (Gelman, 2000)

Las pérdidas que sufrió Gelman - humanas, geográficas, culturales, lingüísticas, profesionales - condujeron a una pérdida total de orientación y referencias, hasta el punto de sentirse "fuera del tiempo": "Son las cuatro de la bestia y nadie despierta." (Gelman, 2001b, p.128). Como bien lo explica la escritora Tununa Mercado (1998), que se exilió en Méjico durante la última dictadura argentina, el tiempo del exilio "se parece más a la idea de horizonte" (p.20); en otros términos, no se conoce su duración y, por ende, el exiliado se encuentra en permanente "espera de". Ella va hasta hablar de "paréntesis" del exilio, el 
cual ocasiona automáticamente un desfasaje entre el tiempo físico y el tiempo psicológico de la persona exiliada; tiempos que el lingüista Étienne Klein (2001) considera en permanente oposición:

Tiempo físico y tiempo psicológico se diferencian también por el hecho de que el primero, concentrado puntalmente siempre en el presente, separa lo infinito del pasado de lo infinito del futuro, mientras el segundo mezcla, adentro del presente, un poco del pasado reciente y un poco del porvenir cercano. [...] Nuestra estimación de las duraciones varía con la edad, y sobre todo con la intensidad y la significación para nosotros de los acontecimientos que se producen. (pp.8-11)

El "paréntesis" del exilio provoca irremediablemente la puesta en suspenso del individuo que mide el tiempo en función de sus sensaciones. Ante la total ignorancia de su vuelta al país, de la suerte de su hijo y de su nuera embarazada, Gelman se ve obligado a vivir en la incertidumbre más completa, cual bestia al acecho, incapaz de proyectarse o de racionalizar una situación límite: "en esta medianoche del exilio/soy yo mismo una bestia/" ("la puerta", Gelman, 2002, p.456). En definitiva, el exilio y la muerte convirtieron la vida cotidiana del poeta en lucha permanente contra sí mismo.

Si Gelman llega a asimilarse con la figura de la bestia en el verso citado anteriormente, cabe señalar que tiende más frecuentemente a relacionarla con el militar:

Los militares llamaban El Vesubio a

un campo de concentración situado

a pocos metros de la autopista General Richieri.

Así lo bautizaron por

la columna de humo negro que

subía de compañeros mezclados

con fuego de neumáticos. Los

que fueron alegres mataban

la alegría del aire. Las bestias

desorganizan los misterios y crean

el misterio de la iniquidad.

Hay momentos en que la vida es

una bruma que no se puede navegar.

El fracaso del corazón cae en la tarde como

un pájaro olvidado del vuelo.

Ese no ser se parece a la noche

que orina mi alma. ("¿O no?", Gelman, 2001b, p.59)

Comparación transparente entre los campos de concentración argentinos y alemanes, "¿O no?" ilustra la crueldad de los verdugos. En realidad, en este 
caso, la bestialización no se refiere tanto a lo que son los militares sino, más bien, a los actos que los hicieron ubicarse en una posición difícil de comprender para el entendimiento humano. Por ejemplo, negarse a confesar dónde están los cuerpos de los desaparecidos, el pacto de silencio impuesto por la cúpula militar, el robo de bebés y demás comportamientos crueles son algunos de los elementos que revelan la intencionalidad de no recurrir a las herramientas de comunicación usuales entre seres humanos. Desde esta perspectiva, se puede considerar el término "bestia" como la expresión no tanto de la inhumanidad sino, mejor dicho, de la pérdida de humanidad de los militares que fueron en contra de los derechos humanos inalienables (tortura, privación de la libertad, impunidad, negación de la memoria, etc.). En definitiva, no solamente se designa al militar en tanto torturador "físico" sino también y sobre todo "moral", actuando tanto en los CCD como afuera o en democracia, como lo podemos vislumbrar en La junta luz:

madre :

Así que jueces, generales, bestias, dicen que no $[\ldots]$ está más aquí

¿Así que esas bestias ignorantes dicen que no $[\ldots]$ estás más aquí?

(se toma el vientre) por aquí volás/hijo

¿y esas bestias dicen que no estás más aquí? (Gelman, 2001a, pp.63-65)

Este extracto de La junta luz (1980) pone en escena una madre de Plaza de Mayo que se rebela contra la complicidad de los poderes militares y judiciales que permiten la impunidad y, por ende, avalan los crímenes de lesa humanidad cometidos entre 1976 y 1983. En ese sentido, este poema tiende a señalar los efectos nefastos de la injusticia que impide cualquier trabajo de duelo. La metamorfosis de los verdugos remite pues precisamente a dos aspectos de su bestialidad de los cuales el segundo es la continuación del primero: uno por acción (la tortura y la desaparición), el otro por omisión (silencio, negación de la memoria). En consecuencia, la "bestia" viene a encarnar el horror impune que va en contra de las necesidades personales y colectivas de hacer un duelo a partir de la recuperación de los cuerpos, de la identificación y señalización de los lugares de memoria para (re)construirse. Extraña casualidad, esta misma función del término "bestia" se puede encontrar en un poema compuesto en una cárcel de la dictadura, por un preso político: 


\section{$[\ldots]$}

Solamente moriremos,

en la mente de las bestias,

pero en el corazón de nuestro pueblo,

en el canto de los niños del mañana,

y en el vuelo de las blancas palomas,

el fuego de la vid será eterno ("Volveremos" [s.f], CADHU, 1981, p.67).

¿Gelman habrá tenido conocimiento de este poema? ¿Habrá intuido que algunos de los secuestrados nombraban así a los militares? En realidad y pese a un accionar en parte ilegal de la represión, muchos actos infrahumanos eran conocidos por la sociedad (la aparición regular de cuerpos en la vía pública y la difusión en los diarios, la desaparición de personas, el encarcelamiento masivo, el terror instaurado en el sociedad, etc.). Dicho de otro modo, la "bestialidad" del régimen autoritario no solamente se "sospechaba" sino que se sufría y estaba "exhibida" diariamente a través de actos concretos y mediante una retórica perversa destinada a demostrar poder. Por ejemplo, así como Gelman lo expresa en su poema, los militares solían bautizar los centros clandestinos de detención con nombres sórdidos - como en el caso del "Vesubio"- que venían sumándose a la "jerga represiva" ya existente ${ }^{15}$.

Es importante agregar también que la "bestialización" de los verdugos en la poesía de Gelman puede aludir - además de la violencia verbal y de los crímenes que cometieron - a la verdadera y concreta animalización de los secuestrados, denunciada por varios sobrevivientes y familiares de víctimas:

En el caso de mi esposo, luego me lo confirman en el juzgado, la tortura continuaba en la celda con micrófonos en las paredes donde se emitían sonidos de animales y chillidos, que despiertan una especie de psicosis con alucinaciones auditivas, diagnóstico que confirma la Cruz Roja Internacional cuando los veo en Devoto. (VV.AA, 2006, p. 133)

Si este testimonio denuncia el hostigamiento - llevado a un punto extremo - mediante "sonidos de animales", otros son más duros aún y dan a conocer prácticas infrahumanas, como lo recuerda Pilar Calveiro (2006) en Poder y Desaparición:

15 Son muchos los eufemismos y las ironías utilizados por los militares. Para dar algunos ejemplos, se puede citar a la "detención", el "interrogatorio" y el "traslado" que denominaban en realidad el secuestro, la tortura y el asesinato de las víctimas también llamadas "paquetes". Asimismo, los nombres de los CCD revelan la perversidad de los verdugos: "Escuelita", "La Huerta", "La Ribera", "La Perla" o "Universidad", "El Refugio", "El Chalecito", "El Embudo", "Sheraton", etc.; sin olvidar que, en algunos CCD, la sala de tortura era la "sala de terapia intensiva". Todas estas informaciones se pueden encontrar en CONADEP, (informe de la Comisión Nacional sobre la Desaparición de Personas), (2006), Nunca Más, Buenos Aires, Eudeba. 
Obligar a las personas a exhibirse y permanecer desnudas ante extraños, lo hacían en todos los campos; hacerlas adoptar posturas ridículas y humillantes, como correr estando encapuchados o atarlos del cuello como si fueran perros (La Perla y Escuela de Mecánica); sumirlos en un terror que los haga temblar (Mansión Serré); forzarlos a pelear entre sí estando encapuchados (Campo de Mayo); llevarlos hasta la desesperación por el hambre para que sólo piensen en la comida y luego devoren el alimento como bestias (comisaría de Castelar); hacer que una mujer desnuda y con los ojos vendados tenga un parto en medio de insultos (Brigada de Investigaciones de Banfield) son sólo algunas de las prácticas que constan en los testimonios y que se usaron para inducir un comportamiento aparentemente animal que justificara el tratamiento posterior de esos seres humanos como si en verdad no fueran hombres. [...] La intención es clara: destruir al sujeto y retraerlo a una existencia casi exclusivamente animal como si realmente se pudiera "animalizar" al hombre. (pp.100-101)

Consideramos pertinente relacionar estos testimonios con la poesía de Juan Gelman y la animalización que hace de los represores en la medida en que fue él quien escribió el prólogo de la obra que acabamos de citar, destacando este mismo fenómeno: "[...] la arbitrariedad de los victimarios, señores de la vida y la muerte, su voluntad de convertir a la víctima en animal, en cosa, en nada." (Gelman en Calveiro, 2006, pp.5-6).

La recurrencia de la figura del "militar-bestia" en la poesía de Gelman pone de relieve, pues, que la voluntad de animalizar a sus víctimas transformó a los verdugos en bestias salvajes. De hecho, lo atestiguan varios sobrevivientes al declarar que algunos verdugos se descontrolaban y desfiguraban a la hora de torturar. Privando las víctimas de sus libertades fundamentales en los CCD, los militares intentaron reducirlos a seres de instinto puro. Dicho de otro modo, la animalización tenía el objetivo de oponer el hombre (militar) al animal (víctima), quitándole todo derecho a la dignidad porque la dignidad es un derecho adquirido - supuestamente - para el hombre pero discutible y discutido para el animal. En efecto, ¿bajo qué criterio se puede evaluar la dignidad debida al animal si tomamos en cuenta, por un lado, la teoría de Descartes quien considera el animal como una máquina (desprovisto de razón); y, por otro lado, la teoría kantiana, la cual opone el hombre - dotado de un valor intrínseco- a la cosa o al animal, que no lo tiene (Baertschi, 2005, p. 186)?

Pero en el caso argentino, como lo explicó Calveiro, la meta de los militares era precisamente aniquilar - física y psicológicamente- bajo la justificación - fabricada - de que las víctimas no merecían trato humano; desde ahí, se entiende la razón por la cual Gelman convirtió al militar en bestia, en "animal- 
maquina", desprovisto de toda noción ética. Más aun, en varias oportunidades, el poeta va hasta recurrir a sinécdoques como "botas militares" (Gelman, 2001a, p.67), o perífrasis como "las botas del dictador" (Gelman, 2001a, p.67) que son otra forma de acentuar la bestialidad de los verdugos, privados de rasgos humanos y reducidos a sus calzados - probable alusión al ruido agresivo del paso militar que se acerca a la celda del prisionero destinado a la tortura o la muerte-. Por haber querido quitar a la víctima su derecho inalienable a la identidad (tortura, animalización, asignación de un número al entrar a un CCD (CONADEP, 2006, p.67), etc.), Gelman replicó borrando -aunque sea solamente en sus poemas - la cara del militar.

\section{Conclusión}

En definitiva, el análisis de los términos "animal" y "bestia" en la poesía de Gelman evidencia una clara intención de nombrar sentimientos ambivalentes resultantes de distintas situaciones límite. Relacionados con el dolor, lo impalpable, lo inefable, ambos términos y conceptos son la manifestación de lo incontrolado, lo descontrolado, lo desconocido. La multiplicidad de significados que contienen es sorprendente y nos ayuda a entender la complejidad de racionalizar ciertas experiencias. Si la poesía le permite a Gelman verbalizar algunas de sus preocupaciones e inquietudes, no le da las respuestas que le tendrían que dar los genocidas y que sigue exigiendo, desde Anunciaciones hasta Valer la pena pasando por su discurso al recibir el Premio Cervantes:

Pero hay recuerdos que no necesitan ser llamados y siempre están ahí y muestran su rostro sin descanso. Es el rostro de los seres amados que las dictaduras militares desaparecieron. Pesan en el interior de cada familiar, de cada amigo, de cada compañero de trabajo, alimentan preguntas incesantes: ¿cómo murieron? ¿Quiénes lo mataron? ¿Por qué? ¿Dónde están sus restos para recuperarlos y darles un lugar de homenaje y de memoria? ¿Dónde está la verdad, su verdad? La nuestra es la verdad del sufrimiento. La de los asesinos, la cobardía del silencio. Así prolongan la impunidad de sus crímenes y la convierten en impunidad dos veces. (Gelman, 2008, p.4)

Mediante su poesía, no se limita a hacer memoria, sino que reclama incansablemente por la verdad y la justicia, luchas que llevó a cuestas hasta su último día. 


\section{Referencias bibliográficas}

BAERTSCH, Bernard (2005) Enquête philosophique sur la dignité. Ginebra: Labor et Fides.

BAY ALMANY, Carmen (2006) "Para una revisión de la poesía conversacional". En: Bay Alemany, Carmen. Residencia en la poesía: poetas latinoamericanos del siglo XX. Cuadernos de América sin nombre 13; pp. 159-171.

CALVEIRO, Pilar (2006) Poder y desaparición. Los campos de concentración en Argentina. Buenos Aires: Colihue.

CELS, (2005) "Los crímenes del terrorismo de Estado, la fuerza de la verdad, el tiempo de la justicia" en Informe 2005, Programa Memoria y Lucha contra la Impunidad del Terrorismo de Estado, dirigido por Carolina Varsky, Valeria Barbuto, Florencia Plazas. Recuperado el 23 de abril de 2008 en: http://www.cels.org.ar/common/ documentos/Informe2005_capitulo1_memoria.pdf

CADHU Comisión Argentina de Derechos Humanos (1981) Desde la cárcel, presos políticos argentinos. México: Asociación de Escritores de México.

CONADEP (informe de la Comisión Nacional sobre la Desaparición de Personas) (2006) Nunca Más. Buenos Aires: Eudeba.

GARCÍA, Antonia, (2000) "Por un análisis político de la desaparición forzada". En: Richard, Nelly (ed.), Políticas y estéticas de la memoria, Santiago: Cuarto Propio; pp. 87-92.

GELMAN, Juan, (23 de abril de 2008) "Discurso", en Elpaís.com, Madrid. http://www.elpais. com/elpaismedia/ultimahora/media/200804/23/cultura/20080423elpepucul_1_ Pes_PDF.pdf

GELMAN, Juan (2002) [1994] De palabra. Madrid: Visor libros.

GELMAN, Juan (2001a) Anunciaciones y otras fábulas, Buenos Aires: Seix Barral.

GELMAN, Juan (2001b) Valer la pena, Buenos Aires: Seix Barral.

GELMAN, Juan (26 de noviembre de 2000). "Discurso de Juan Gelman", en La insignia.org. http://www.lainsignia.org/2000/noviembre/cul_057.htm.

H.I.J.O.S Regional Córdoba en la Red Nacional, (2008) Condenados. Documento histórico Primer Juicio a Genocidas en Córdoba 27 de Mayo 2008-24 de Julio de 2008, Córdoba: Imprenta H.I.J.O.S.

KLEIN, Etienne, (2001) "Le tic tac des physiciens", en La Recherche, Hors-Série, 5, "Le temps", París ; pp.8-12.

LEWIN, Miriam y WORNAT, Olga (2014). Putas y guerrilleras. Buenos Aires: Planeta.

LONGONI, Ana (2007) Traiciones, la figura del traidor en los relatos acerca de los sobrevivientes de la represión. Buenos Aires: Norma.

MERCADO, Tununa (1998) En estado de memoria. Córdoba: Alción.

PAZ, Octavio, (1997) [1950]. El laberinto de la soledad, New York: Penguin Books.

PIÑA, Cristina, (1993) "La narrativa argentina de los años setenta y ochenta". En: Malpartida, Juan (director), La cultura argentina: de la dictadura a la democracia, 
Amandine Guillard

Cuadernos Hispanoamericanos 517-519, Madrid: Agencia Española de Cooperación Internacional y Desarrollo; pp. 121-138.

ROBIN, Marie-Monique (2004). Les escadrons de la mort, l'école française. París: La Découverte.

SCHÜTZ, Alfred, (2003) Estudios sobre teoría social, Buenos Aires: Amorrortu.

SOSNOWSKI, Saúl (1983) "La dispersión de las palabras: novelas y novelistas argentinos en la década del setenta", en Revista Iberoamericana, vol. XLIX, 125; pp. 955-963.

V.AA, (2006) Nosotras, presas políticas. Buenos Aires: Nuestra América. 